\title{
Imagens do sexo: as falsas fronteiras do erótico com 0 pornográfico
}

\section{RESUMO}

Os conceitos de "erótico" e "pornográfico" são costumeiramente usados para demarcar os filmes com cenas de sexo que podem ser vistos pelo público em geral e aqueles que estão limitados a um mercado subterrâneo. Este ensaio analisa criticamente esta divisão e propõe uma outra, mais adequada para uma visão crítica dos jogos de poder que envolvem a indústria audiovisual.

\section{PALAVRAS-CHAVE}

- cinema

- erotismo

- pornografia

\section{ABSTRACT}

The concepts of "erotic" and "pornographic" are used to put a line between the films with sex scenes that can be screened to all audiences and the $x$-rated films, that are distributed in an underground market. This article analyses critically this division and considers another one, better for a critic vision of the power games of the audiovisual industry.

\section{KEY WORDS}

- cinema

- erotism

- pornopgrahy

\section{Carlos Gerbase FAMECOS/PUCRS}

D istinguir, no âmbito das narrativas fílmicas, onde termina o campo do erotismo - aceito, mesmo que com reservas, como um lócus sério do cinema - e onde começa a pornografia, desde sempre relegada ao submundo e tratada como uma espécie de crime estético, é tarefa das mais complicadas. Propomos listar algumas tentativas - que consideramos equivocadas - de estabelecimento dessas fronteiras e refletir sobre a origem desses equívocos, além de propor uma explicação para esse embate conceitual que contribua para um entendimento menos cartesiano da questão.

A existência destes dois conceitos - "erótico" e "pornográfico" - no campo do cinema parece ter finalidade instrumental, isto é, deveria ajudar o espectador a escolher o filme mais adequado ao seu gosto e evitar enganos ou constrangimentos. $\mathrm{O}$ público padrão do cinema "pornô" consome, sem maiores problemas, um filme "erótico", e talvez fique apenas um pouco decepcionado com a ausência de imagens explícitas. Já o consumidor de um filme apenas "erótico" pode sentir-se ultrajado frente a cenas consideradas padrão numa narrativa "pornográfica".

Como veremos mais tarde, essa separação é muito mais que instrumental. Mas, mesmo nos limites de uma visão funcional e pragmática, alguns problemas começam a surgir quando os filmes têm que ser colocados objetivamente numa das duas classificações, partindo de suas supostas e distintas características estéticas. Vejamos algumas tentativas:

1 Distinção plástica - um filme "pornográfico" mostra a genitália masculina e/ou feminina em ação sexual, enquanto um filme "erótico" mostra a ação dos amantes, mas esconde a genitália. Ou até mostra a genitália, mas os órgãos estão em posição de descanso. PROBLEMA: há vários filmes contemporâneos com cenas de sexo, mostrando a genitália em ação, que não são classificados como pornográficos, e sim como obras de arte erótica, com direito a prêmios em festivais e críticas nas revistas. Podemos citar, entre outros, "O império dos sentidos" (de Nagisa Oshima, 1976), "Romance" (de Catherine Breillat, 1999), "O pornógrafo" (de Bertrand Bonello, 2002) e “Nove canções" (de Michael Winterbotton, 2004).

2 Distinção psicológica - uma cena "pornográfica" restringe a representação do ato sexual aos seus componentes mecânicos, enquanto uma cena "erótica" considera as relações psicológicas (emocionais) presentes naquela relação. 
PROBLEMA: como separar o desejo sexual dos demais sentimentos (amor, carinho, afeição, etc.)? Como considerar que, numa cena de sexo, em que um homem está com o pênis ereto, não há um componente emocional e psicológico? Isso só seria possível se a ereção pudesse ser controlada racionalmente (mecanicamente), por um ato de vontade. Ora, num mundo assim, a impotência nunca seria um problema, e o Viagra teria menos valor que a aspirina.

3 Distinção intuitiva - daquele que diz: "Não sei conceituar pornografia, mas sei perfeitamente quando estou diante dela". PROBLEMA: a intuição é arma poderosa para o conhecimento. Qualquer processo cognitivo necessita de uma dose de intuição, especialmente em sua origem. Mas, daí a dizer que é possível separar o "pornográfico" do "erótico" numa avaliação intuitiva, é uma simplificação grosseira. $\mathrm{O}$ intuicionismo, ao contrário do que muitos pensam, é histórico e cultural (além de ser subjetivo). Assim, os julgamentos apenas intuitivos são todos extremamente individuais (e, portanto, quase inúteis). Quase sempre essa distinção intuitiva é defendida por um avaliador dogmático quem não tem qualquer argumento teórico.

4 Distinção estética - uma obra "erótica" seria, necessariamente, de "bom gosto", enquanto a "pornográfica" resvalaria para o terreno do "mau gosto". PROBLEMA: os critérios de valoração estética também são históricos, culturais e ideológicos. Como Nietzsche mostrou, a filosofia ocidental ataca ferozmente o corpo e os sentidos desde Platão, de modo que quase todas as manifestações instintivas ou emocionais do ser humano são classificadas, a priori, como negativas, ruins, de "mau gosto". O ideal ascético domina a filosofia, enquanto os hedonistas são, na melhor das hipóteses, imorais (e muitos são considerados dementes, ou criminosos).

5 Distinção funcional - o material pornográfico seria sempre de uso prático (para excitar), enquanto o erótico poderia ter fins mais "nobres" (simples apreciação estética). PROBLEMA: na falta de material pornográfico, um adolescente é capaz de se excitar com a foto de uma mulher vestida da cabeça aos pés, tão pura quanto um anjo (para todos, menos para o adolescente em questão). Na presença de material pornográfico, muitos homens e mulheres têm uma reação muito distante da excitação: ficam envergonhados, sem-jeito, chocados. A recepção de uma obra depende de inúmeros fatores que não fazem parte da obra, e sim do receptor. E mais: o uso de uma obra, muitas vezes, está distante das intenções de seu autor.

6 Distinção narrativa - em seu ensaio "Como reconhecer um filme pornográfico" (1999), Umberto Eco primeiro afirma que os pornôs são aqueles filmes que "têm como único e verdadeiro objetivo estimular o desejo do espectador, do começo até o final" (p. 163), o que colocaria o pensador italiano como um adepto da distinção funcionalista. Depois, Eco estabelece outro tipo de diferença, baseada no "cálculo do tempo desperdiçado" (p. 163): "Se Gilberto tem que pegar um ônibus para ir de A para B, nós veremos Gilberto pegando o ônibus e então o ônibus indo de A para B" (p. 164), o que para Eco configura um tempo "mais longo que você esperaria” (p. 164). Essa seria a característica identitária dos filmes pornográficos: o absurdo desperdício de tempo narrativo. PROBLEMA: a piada é boa, mas não se aplica a todos os filmes pornográficos. Alguns são extremamente econômicos nas cenas nãosexuais; outros simplesmente não têm cenas nãosexuais. Filmes pornôs realizados por diretores experientes podem ter narrativas mais ágeis e econômicas que a grande maioria das obras da "nouvelle-vague".

7 Distinção pela distância - Michael Koetzle (1994) tenta distinguir três categorias de imagens que envolvem nudez:

distância é o que define o nu artístico, proximidade define a fotografia erótica, além, é claro, do sorriso encorajador e do olhar brilhante e lúbrico. Nus que aspiram a um status artístico procuram seguir a regra de que 'menos é mais', enquanto a fotografia erótica é caracterizada por 'quanto mais, mais divertido'. Nus artísticos não fazem promessas, nus fazem algumas, e trabalhos obscenos ou pornográficos trabalham tão completamente para satisfazê-las que muitos espectadores os consideram mais ofensivos que excitantes (p.17).

PROBLEMA: Koetzle introduz uma nova categoria, o "artístico", que tem sentido na fotografia, mas parece inútil no cinema. A maioria dos filmes "eróticos" são classificados como "artísticos" (ao contrário dos pornográficos). Além disso, deixar o julgamento para o espectador é, inevitavelmente, tornar a distinção subjetiva, histórica e cultural. Por outro lado, dizer que um nu artístico não faz promessa alguma é subestimar a capacidade do público de interpretar a nudez num determinado padrão psicológico. Digamos que, considerando os limites da interpretação estabelecidos por Eco (1995), o público não pode "ver" uma promessa de sexo numa mulher vestida como camponesa, tapada da cabeça aos pés, alimentando galinhas, mas pode interpretar eroticamente uma cena em que a camponesa entra em casa e, para se refrescar, abaixa um pouco as alças do vestido e passa um pano molhado nos ombros. 
8 Distinção comercial: talvez esta seja a mais objetiva de todas. Num determinado contexto histórico e geográfico, a sociedade (num julgamento que talvez considere todos os itens acima, ou uma combinação qualquer de determinados pontos de vista), pragmaticamente separa (segrega) os bens de consumo considerados eróticos, e os que são chamados de pornográficos, delimitando espaços específicos para os dois campos. Numa locadora de vídeo, há uma seção de filmes "eróticos" (misturada com as demais seções) e uma de "pornográficos" ou "para adultos" (separada, normalmente em sala especial). Numa banca de revistas, há prateleiras para a "Playboy" - e crianças comparecem à sessão de autógrafos da modelo da capa - e prateleiras para revistas que uma criança, a princípio, não pode sequer olhar. Algumas dessas revistas - mas não todas - são vendidas em embalagens plásticas, que impedem seu manuseio. No menu de um serviço de TV a cabo, há canais com programas eróticos, normalmente abertos, enquanto os canais exclusivamente pornográficos são fechados (por assinatura, dependendo de senha). PROBLEMA: há uma mobilidade muito grande entre estas classificações (e seus produtos), dependendo do dono da locadora, do proprietário da banca de revistas ou do responsável pela programação do serviço de TV. A distinção pragmática funciona, mas depende demais do contexto histórico e geográfico em que é estabelecida.

Nenhuma destas distinções resolve nosso problema. Cremos que é necessário cavar um pouco mais fundo para procurar as raízes da distinção do "erótico" e do "pornográfico".

\section{Voltando às origens}

Aristóteles já percebera, em IV A.C., que há uma ligação evidente entre as origens do que chamava de "mimese" - e que hoje poderíamos traduzir como "representações do mundo" - e prazer. A criança, desde bebê, adquire conhecimentos fundamentais (entre eles, as convenções da linguagem) ao imitar os seres que estão próximos, e esse conhecimento só é possível porque é impulsionado pelo prazer do ato imitativo. Depois, ao entrar na escola, terá de sujeitar-se a uma assimilação quase sempre nãoprazerosa, mas é evidente que aprenderá mais e melhor sempre que as lições forem acompanhadas de um mínimo de satisfação emocional.

Vendo essa questão pelo seu inverso, o que era uma das especialidades de Nietzsche, poderíamos dizer que a origem das representações artísticas do mundo está na necessidade humana de inventar o próprio prazer, sempre que este não estiver disponível em sua forma primitiva e explicitamente sexual. Sendo o único animal a experimentar o tédio enquanto importante situação existencial - nada provoca mais angústia que a sensação de um tempo vazio, que passa sem propor sentidos para a vida - o homem é obrigado a criar brincadeiras, que evoluem e se sofisticam até se tornarem o que chamamos de arte. Por enfrentar a experiência do Nada e para fugir do niilismo (aqui considerado apenas em seus aspectos negativos, de derrota frente ao destino), o homem acaba transformado por esse Nada num animal diferente de todos os demais. Ao brincar com o mundo, o reproduz das mais variadas formas, desde as mais abstratas (a música, por exemplo, grande paixão de Nietzsche) até as mais concretas (o cinema, por exemplo, cujo grau de verossimilhança é extraordinário).

Rüdiger Safranski destaca a capacidade do filósofo em transitar com liberdade - e coragem - nos espaços entre o corpo e o espírito: "Nietzsche é um virtuoso dessa relação fronteiriça entre física e metafísica. Ele sabe conferir um novo encanto metafísico aos seus desencantos fisiológicos" (2001, p. 17). Cremos que essa dupla abordagem - material e espiritual - dos limites entre os campos erótico e pornográfico é a única que pode fornecer resultados relevantes, que fujam da simples piada acadêmica (ao modo de Umberto Eco), da simplificação moralista e dogmática (que costuma estabelecer fronteiras por decreto) e de um certo humanismo ingênuo (que ainda dá ao sujeito plena consciência de suas escolhas éticas).

Ao mesmo tempo, quando propomos misturar questões instintivas e biológicas com reflexões estéticas criamos um grande perigo: estabelecer um movimento pendular entre estes campos que, embora seja atrativo (e talvez até hipnótico), não avança no problema. E como fica o rigor científico, a objetividade dos fatos, se admitirmos o sexo - em toda a sua complexidade emocional, em seu subjetivismo quase irredutível a leis e regras constantes - como componente fundamental dessa análise? Não estaríamos confundindo o objeto estético do estudo (filmes com cenas de sexo) com o pragmatismo de nossas vidas? Não estaríamos embriagando a reflexão teórica com a "loucura" que o sexo faz acontecer no cotidiano? Lou Andreas-Salomé, contemporânea de Nietzsche e, de certa forma, ligada à sua trajetória intelectual, afirma que esses medos devem ser enfrentados e superados:

(...) Alguma coisa de valor supremo, humano, se perde na experiência sexual, quando a loucura humana que provoca é afastada com as costas da mão, como se fosse algo negligenciável. Só através das mais delirantes efusões dos amantes de todos os tempos e de todos os povos se completa o inventário do que o homem fez do sexo, deixando essa febre arrastar sua inteligência: e isso quando não as consideramos nem como românticas nem com um interesse mais ou menos médico (1991, p. 30).

Assim, seguindo os conselhos de Nietzsche e Andreas-Salomé, em vez de simplesmente partir do objeto do estudo (os filmes que contêm representa- 
ções do sexo), vamos considerar primeiro as relações históricas entre os mecanismos do poder e a sexualidade humana, deixando que esta ocupe o centro da arena, em vez de permanecer como simples "fonte" ou "tema" para representações artísticas.

\section{Estratégias do poder e primeiras respostas dos corpos}

Ao contrário dos outros animais, submetidos às regras biológicas do cio, que estabelecem períodos eventuais para o sexo, o homem pode pensar e praticar sexo o tempo todo. Isso, embora pareça positivo, gera alguns problemas graves. $\mathrm{O}$ ataque que a filosofia ocidental, desde Platão, fez ao corpo erótico, em nome de um ideal ascético e racional, comprometido com o bem social, e não com o prazer individual, é devastador. A repressão ao instinto sexual, que já foi muito concreta e material - sugerindo, inclusive, que os homens cortassem seus órgãos reprodutivos - foi se transformando, na modernidade, numa bula de castração psicológica, em que a noções de culpa e pecado fazem parte da posologia e do modo de usar.

Foucault, por outro lado, provou que os mecanismos mais eficientes de controle social não são repressores e negativos. São criadores e positivos. O poder (no sentido usado por Foucault) faz o sexo falar, se manifestar, se posicionar (de um modo mais sutil ou mais explícito, dependendo dos limites morais de cada tempo e de cada cultura). Enfim, faz o sexo aparecer, em vez de sumir (o que, no final das contas, é fisiologicamente impossível, pelo menos no atual estágio da humanidade). Essa estratégia, é claro, não tem um objetivo libertário. Ela visa a substituir a prática erótica dos corpos por um discurso erótico dos espíritos que já vem com todas as contra-indicações sublinhadas na bula.

Em vez de o sexo funcionar como um momento de totalidade do Ser, em que os corpos vingam-se da morte e atingem, num transe febril e louco, a fusão do material e do espiritual, o poder cria um sexo que, na prática dos corpos, deve ficar restrito à sua função reprodutiva, racional, dentro do casamento monogâmico, ficando todo o resto - a loucura, a embriaguez, a transcendência - como uma produção incessante (patrocinada pelo poder e altamente rentável economicamente) de discursos eróticos, quase sempre vazios e contaminados pelo moralismo mais rasteiro. Uma estratégia eficiente, quase universal, que funciona tanto num barraco de vila popular de um país subdesenvolvido quanto numa sala de aula de universidade do primeiro mundo.

A idéia de que "os filmes eróticos são um mundo de sonhos onde vivemos, sem pecado ou vergonha, as infinitamente gratificantes fantasias sexuais que nos são vedadas na vida real" (KEESEY \& DUNCAN, 2005, p. 9) não passa de propaganda enganosa. O pecado e a vergonha - e, muitas vezes, a punição com a morte do personagem que ousa realizar suas fantasias sexuais - fazem parte da grande maioria dos filmes eróticos desde "A fool there was", o filme que lançou Theda Bara, a primeira "vampira" de Hollywood. Os próprios Keesey e Duncan, em seu livro "Cinema Erótico", admitem que esse "mundo dos sonhos" não é, necessariamente, tão gratificante quanto parece:

Alguém disse que o intenso apelo erótico das estrelas de cinema é perigosamente sedutor, levando-nos a um mundo fantasioso de perfeita, mas falsa, realização. 'A maioria das pessoas não tem energia para a verdadeira paixão, por isso desistem e vão ao cinema', diz Jeanne Moreau, e Naim Kattam alerta: 'A fotografia de uma estrela de cinema conduz, não a um momento de prazer sensual com uma mulher viva, mas a outra fotografia de outra estrela, mais atrevida e provocadora que a primeira' (idem, p. 9).

Como os corpos, inevitavelmente frustrados por essa espécie de sexo virtual que nunca se atualiza, conseguem resistir e, forjando sua estratégia de contra-ataque, permanecem humanos, em vez de simples invólucros do mundo das idéias de Platão? Num primeiro momento, devemos contabilizar os sexualmente radicais, que, contra a repressão e a substituição do sexo pelos discursos eróticos, pretendem viver numa sexualidade sem limites, plenamente instintiva, e num hedonismo livre de convenções morais, tanto na prática quanto na criação artística. O destino destes, com Sade à frente, como se sabe, é a marginalidade ou a cadeia. Não parece ser uma boa idéia. Além disso, se o homem optar por uma vida puramente instintiva, será muito mais animal que homem, podendo até se transformar num monstro.

Michael Onfray, na sua "Teoria do Corpo Amoroso" (2000), propõe outra saída: substituir o moralismo tradicional (de Platão a Kant) por uma ética hedonista, que

(...) não nega a monstruosidade do ser humano, seu lado de animal nocivo, violento, predador. Pelo contrário, afirma que devemos afastar-nos dos homens desse tipo, dedicar-lhes desprezo e depois, se possível, esquecê-los. O próprio hedonista deve reconhecer que, dentro dele, habita esse animal. Mas, ao contrário das morais de ideal ascético, que propõem a morte desse animal, sua aniquilação, sua castração, o hedonista pretende dominá-lo, domesticá-lo, impor-lhe limites (SANTIAGO, 2002).

Onfray adverte que o hedonismo não pode resultar em violência, e que a sua força deriva da elegância, da beleza e da qualidade de suas práticas. Essa ressalva, contudo, não impede que o sexo continue 
sendo considerado "mau". Na Grécia Antiga, quando aristocracia era a personificação da bondade, do positivo, enquanto os escravos eram a encarnação da baixeza, da negação e da maldade, o sexo hedonista - devidamente vigiado na sua porção animal e restrito aos cidadãos - poderia ser "bom". Porém, com a vitória cultural do judaísmo e do cristianismo, o "bom" passou a ser atributo da simplicidade, da pobreza, da pequenez. E o escravo, que sofria, agora está moralmente acima do nobre, que tinha prazer. Com essa inversão da lógica moral, os exescravos podem se vingar de seus antigos senhores, afirmando que tudo que eles possuíam (ou ainda possuem) é moralmente condenável.

Nieitzsche, bem antes de Onfray, em "Genealogia da moral", já dissera que a moral escrava nasce de um grande "Não" à vida, que compreende um "Não" ao outro como parceiro sexual. Sempre que o "Não" à alteridade vigorar, o mundo e as criações artísticas serão assexuados, desumanos e moralistas.

\section{Uma estratégia possível: transfigurar os corpos}

Temos, então, um impasse existencial, que pode ser compreendido em quatro etapas:

1 Viver em absoluto hedonismo nos transforma em animais, ou pelo menos em humanos marginalizados, sempre à beira do crime;

2 Na prática, é difícil para os corpos viver o sexo em um hedonismo controlado (proposta de Onfray), pois as sanções morais e psicológicas ainda são muito pesadas;

3 Para alguns - talvez a maioria - a operação de substituição do sexo dos corpos pelos discursos eróticos (incentivados e devidamente vigiados pelo poder) é plenamente exitosa, pois a dor psicológica daí resultante é compensada pela aceitação social e pela segurança de uma vida sem maiores percalços: nascem os "normopatas";

4 Para outros - quem sabe uma minoria, mas ainda significativa - é preciso achar uma nova solução, que não caia, nem na marginalidade, nem no hedonismo controlado (privilégio dos mais fortes), nem no simples abandono à mistificação dos discursos eróticos produzidos pelo poder.

Lou Andreas-Salomé (1991) propõe, para desatar esse nó, uma espécie de ressignificação dos discursos e das práticas eróticas tradicionais. E, para ela, a arte cumpre papel decisivo nesse processo, porque é capaz de abrigar, numa só obra ou momento de criação sublime, o todo do ser humano, a soma da animalidade e da racionalidade, dos instintos e do pensamento, da realidade corporal e do sonho espiritual:
Não é raro que todo o comportamento que os amantes têm em sua relação exprima, um pouco, a vaga intuição que apenas se devem mostrar um ao outro transfigurados, velados, e que é necessário - sem a menor pose ou decisão - se conformar como numa obra de feitiçaria, com a imagem de seu sonho. É que algumas coisas, e as mais belas, só podem de certo modo viver estilizadas, e não de um modo puramente realista, na plenitude de seu ser, como se essa exuberância fantasticamente poética só pudesse ser captada com a ajuda de uma forma igualmente trabalhada; organizada por um desejo respeitoso da Beleza, na qual nos entregamos com extrema contenção, um extremo abandono, e, por isso mesmo, numa combinação completamente nova de nosso ser (1991, p. 32)

Essa transfiguração dos amantes, que viram personagens de si mesmos e assim conseguem superar o tédio de uma realidade sempre igual e aborrecida, é muito parecida com o processo de representação do mundo pela arte. É importante notar, nessa altura, que a arte - e aqui estamos falando do cinema em particular - é uma das fontes mais fecundas dos discursos sobre sexo incentivados pelo poder. Como distinguir o que seria uma obra plenamente artística, que tem o desejo de respeitar a Beleza e dar um pleno "Sim" à Vida e ao Outro, de um discurso que é vassalo do poder, da moral hegemônica, que diz "Não" à alteridade? Isso ainda é mais difícil que separar um filme "erótico" de um "pornográfico". Cremos que não é possível estabelecer classificações rígidas, mas que podemos - e devemos - distinguir algumas escolhas estéticas (que viram existenciais, para os artistas) que estabelecem ênfases para um lado ou para o outro.

Os estímulos de erotismo libertário (e não castrador) seriam bem parecidos com as origens das verdadeiras obras de arte, que teriam com eles

(...) um parentesco profundo, quase se poderia dizer (...) um parentesco de sangue, pois, no ato do artista, entram em ação e emergem, sob as forças individualmente adquiridas, forças arcaicas de uma apaixonada emoção. Ambos os casos integram misteriosas sínteses do passado e do presente, o que constitui a experiência fundamental, e nos dois casos existe a embriaguez de sua interação secreta (ANDREASSALOMÉ, 1991, p. 33).

Um pouco adiante, Lou Andreas-Salomé é ainda mais clara:

“... como o instinto de criação estética e o instinto sexual apresentam analogias tão extensas que o êxtase estético desliza insensivelmente em êxtase erótico e este tenta involuntariamente se 
dotar de um adorno estético - ou talvez este tenha revestido diretamente a animalidade, tendo o corpo como matéria de criação - tais fatos parecem demonstrar um sentimento geminado a partir da mesma raiz" (1991, p. 34).

Nietzsche já tinha observado essa transfiguração dos corpos, mas a considerava um atributo do gênero feminino. Para o filósofo, as mulheres, sempre motivadas pelo amor, são capazes de se transformarem nas imagens mentais que seus amantes têm delas. Essa espécie de "mentira narrativa" (ou "adorno estético", na feliz expressão de Andréas-Salomé) não é construída para substituir a prática sexual, e sim para torná-la possível, ou até mais prazerosa.

\section{Re-humanizar o sexo, re-filmar o erotismo}

Na sociedade do espetáculo descrita por Guy Debord (2000), o sexo certamente tem uma função importante: ele é matéria-prima para a fabricação de mercadorias "espetaculares" de grande valor simbólico e econômico. Nas palavras de Debord:

"Por esse movimento essencial do espetáculo, que consiste em retomar nele tudo que existia na atividade humana em estado fluido, para possuí-lo em estado coagulado, como coisas que se tornaram o valor exclusivo em virtude da formulação pelo avesso do valor vivido, é que reconhecemos nossa velha inimiga, a qual sabe tão bem, à primeira vista, mostrar-se como algo trivial e fácil de compreender, mesmo sendo tão complexa e cheia de sutilezas metafísicas, a mercadoria" (2000, p. 27).

A indústria cinematográfica, desde os seus primórdios, é grande especialista na "coagulação" do sexo, na sua transformação em mercadoria. Contudo, os bens fabricados, para serem socialmente aceitos, precisam se adequar a certas práticas e normas, a saber:

1 Respeitar a censura de cada País, que tenta determinar, na legislação, o que pode ou não pode ser visto;

2 Para amenizar essa censura (e ampliar o mercado de consumo), os filmes "sérios" ou "de arte" (não pornôs) devem conter uma mensagem moralista (estratégia dos filmes de "vamps");

3 Nos pornôs, em vez de mensagem moralizante, apresentar o sexo como espetáculo puramente plástico, desumano e sem emoções (e, assim, além das questões morais).

Nos três casos acima, trata-se de retirar da representação do sexo qualquer traço de uma verdadeira "embriaguez" dos sentidos (conforme descrita por
Andréas-Salomé e só possível no mundo concreto), que é substituída por coisas "supra-sensíveis" (DEBORD, 2000, p. 28), nada além de uma "seleção de imagens que existe acima [do mundo sensível], e que, ao mesmo tempo, se faz reconhecer como o sensível por excelência" (idem, p. 28).

Essa é a grande esperteza da maioria dos fabricantes de obras audiovisuais com sexo (eróticas ou pornográficas): mantê-las longe de qualquer transbordamento exagerado dos sentidos. E, inevitavelmente, longe do campo artístico, pois
"para que haja arte, para que haja alguma ação e contemplação estéticas, torna-se indispen- sável uma condição fisiológica prévia: a em- briaguez. A embriaguez tem de intensifi- car primeiro a excitabilidade da máquina inteira: antes disso não acontece arte nenhu- ma" (NIETZSCHE, 1996, p. 84).

Um cinema essencialmente comercial, que trata o filme (erótico ou pornográfico) apenas como uma mercadoria, retirando da representação do sexo qualquer vestígio de transbordamento, de embriaguez, de arte, será sempre um cinema distante do homem. A primazia de uma lógica econômica, numérica, que exige uma determinada performance financeira de um filme, acima de qualquer outra avaliação, costuma "coagular" a representação do sexo. Não se trata de simplesmente ignorar o caráter econômico de um filme, e sim de verificar se este não se transformou no único caráter existente. Na história do cinema, há numerosos exemplos de cineastas que, mesmo mantendo um alto grau de autoria em seus trabalhos, conseguiram êxitos - pelo menos parciais - de bilheteria.

Citaremos três filmes que parecem seguir esse caminho: "O império dos sentidos", de Nagisa Oshima (um filme "erótico" com cenas de sexo explícito), "O último tango em Paris", de Bernardo Bertolucci (um filme "erótico" sem cenas de sexo explícito) e "A massagista", de Paul Thomas (um filme pornográfico). Oshima, Bertolucci e Thomas, cada um à sua maneira e com os recursos possíveis em cada situação, representaram o sexo em sua fluidez, sem coagulá-lo, pois estavam possuídos pela necessária embriaguez emocional.

A morte do personagem masculino de "O império dos sentidos" não é, de modo algum, uma punição moral, e sim o resultado da absoluta entrega ao ato sexual. Já em "O último tango em Paris", o protagonista masculino está em profunda crise existencial, e o sexo, para ele, é uma última oportunidade de agarrar-se à vida. O personagem central de "A massagista", um homem tímido apaixonado por uma prostituta, fará de tudo para não relacionar-se com ela comercialmente, e sim numa base humana e psicológica. Não por coincidência, se tentássemos localizar estas obras nos campos do erotismo ou da 
pornografia, teríamos alguns problemas. Os dois primeiros filmes, após grande sucesso de crítica, alcançaram boas carreiras comerciais. $\mathrm{O}$ terceiro recebeu os prêmios de melhor filme e melhor ator no "AVN Awards", o mais importante certame da indústria pornô e teve excelente vendagem.

Propomos um novo olhar sobre os filmes que contêm sexo em suas tramas. Em vez do dualismo "erotismo versus pornografia", que é uma estratégia da indústria audiovisual para lucrar o máximo possível dividindo o público em "convencional" e "subterrâneo", e, a partir daí, entregar mercadorias que "coagulam" o sexo, propomos uma divisão entre filmes "conformados" e "libertários". É "conformado" todo filme que representa o sexo de acordo com as conhecidas estratégias do ideal ascético (sexo com prazer deve ser punido) e da desumanização das relações (sexo plástico, sem qualquer emoção). É "libertário" todo filme que representa o sexo com embriaguez, que respeita o caráter transcendente do erotismo, que consegue registrar os movimentos dos corpos na busca dos adornos estéticos que permitem uma relação amorosa mais duradoura depois de esgotados os momentos de paixão febril e animal. É libertário o filme que consegue escapar do jugo mercadológico e propor ao espectador uma narrativa que contenha uma visão pessoal, subjetiva e apaixonada do cineasta pela história e pelos seus personagens.

Também é libertário o filme que retira a mulher de sua condição de subserviência ao homem, tradicional em Hollywood. Para Breillat, diretora de "Romance":

“os tabus, proibições e vergonhas que envolvem a sexualidade feminina são necessários porque o desejo provém dos tabus. Mas, ao mesmo tempo, têm de ser transgredidos. Se não puderem ser transgredidos transformamse em moralidade e censura, o que acaba por prejudicar as mulheres" (apud KEESEY \& DUNCAN, 2005, p. 25).

Igualmente libertário é o filme que, em vez de apenas reproduzir a estratégia hollywoodiana da punição ao prazer, consegue ter uma visão crítica dos desafios eróticos propostos aos personagens. Em "Lolita" e, especialmente, em "De olhos bem fechados", Stanley Kubrick reflete sobre as inevitáveis conseqüências psicológicas das "transgressões" (na visão conservadora dos protagonistas) de conduta, mas jamais encampa ou subscreve dogmas moralistas e castradores.

Apresentar o sexo como uma atividade livre de problemas é, de certo modo, fechar os olhos para a realidade. O sexo representado por Pasolini, em "Decameron" e "Os contos de Canterbury" é fácil demais, infantil demais, e parece ser praticado em outro planeta, pois não há transgressão alguma. Os grandes desafios da representação do sexo num cinema esteticamente libertário são, ao mesmo tempo, manter a verossimilhança - e, portanto, considerar todo o contexto social repressivo que envolve os personagens -, afastar-se das estratégias da maioria da indústria - que fornece satisfação erótica virtual, mas sempre seguida de uma grave punição - e propor o sexo como um tema fundamental para a compreensão global da vida humana, a ser tratado livremente e com a complexidade que merece, sem simplificações moralistas, nem interdições dogmáticas.

As fronteiras entre o "erótico" e o "pornográfi$\mathrm{CO}^{\prime \prime}$, assim, deixam de ser importantes, pois apenas demarcam áreas de distribuição. A verdadeira linha divisória está entre os filmes que usam o sexo como recurso comercial, transformando-o em mercadoria para uma sociedade regida por "performances" e sempre medida por números - ascética, maquínica e cada vez mais assexuada (embora poluída por imagens eróticas) - e os filmes que desafiam esse caráter mercadológico, através de uma saudável "embriaguez" dos sentidos, sem a qual não há arte, e que só estará presente nos corpos dos personagens e dos espectadores se, antes, estiver presente nos corpos e mentes dos cineastas. Estes filmes podem, em vez de substituir o sexo, na operação anti-humana bem conhecida da indústria audiovisual, suscitar uma revolta dos corpos, transfigurados na tela e na vida real, em busca de uma vida mais livre e mais feliz. mamecos

\section{REFERÊNCIAS}

ANDREAS-SALOMÉ, Lou. O erotismo, seguido de reflexões sobre o problema do amor. São Paulo: Princípio, 1991.

DEBORD, Guy. A sociedade do espetáculo: comentários sobre a sociedade do espetáculo. Rio de Janeiro: Contraponto, 1997.

ECO, Umberto. Os limites da interpretação. São Paulo: Perspectiva, 1995.

—. How to recognize a porn. In: ADAIR, Gilbert (org.). Movies. Londres: Penguin Books, 1999.

FOUCAULT, Michel. História da Sexualidade: a Vontade de Saber - vol. 1. São Paulo: Graal, 1998.

JUNG, Carl Gustav. Civilização em transição. Rio de Janeiro: Vozes, 1993.

KEESEY, Douglas \& DUNCAN, Paul (ed.). Cinema erótico. Köln: Taschen, 2005.

KOETZLE, Michael. 1000 Nudes: Uwe Scheid Collection. Köln: Taschen, 1994. 
LEWIS, Jon. Hollywood v. Hard Core: How the Struggle over Censorship Saved the Modern Film Industry. New York: New York University, 2002.

ONFRAY, Michel. Teoria do corpo amoroso. Lisboa: Temas e Debates, 2001.

NIETZSCHE, Frederico. Crepúsculo dos ídolos: ou como se filosofa a marteladas. Lisboa: Guimarães Editores, 1996.

SANTIAGO, Rosana Fontella Santiago. A vida como uma obra de arte: a perspectiva hedonista de Michel Onfray. Porto Alegre: PUCRS, 2002.

THORNHAM, Sue (org). Feminist Film Theory: a Reader. New York: New York University, 1999. 